\title{
WHY DO SOME CHEMICAL REACTIONS OSCILLATE?
}

\author{
A CHANCE DISCOVERY OF AN UNUSUAL OSCILLATORY REACTION BY A \\ RUSSIAN CHEMIST NEARLY 70 YEARS AGO HAS PAVED THE WAY FOR SOME \\ POTENTIALLY EXCITING, MODERN APPLICATIONS. PROFESSOR IRVING EPSTEIN \\ AT BRANDEIS UNIVERSITY, USA, IS INVESTIGATING THE MYSTERIES BEHIND THIS \\ VERY SPECIAL CHEMICAL REACTION
}

\section{TALK LIKE A CHEMIST}

\section{LINEAR PROCESS - a process in} which the observed value is linearly proportional to the input variable

\section{NONLINEAR PROCESS - a process} in which the observed value is not linearly scaled to the input variable

\section{VARIABLE - a quantity that can take} on different values at different times or positions

OBSERVABLE - what you measure or see in a process

OSCILLATION - a periodic change, like the tides in the sea or the motion of a pendulum

CHAOS - non-periodic, deterministic change, like the weather
Sometimes life is simple. You push an object, it moves. You push the same object twice as hard; it moves twice as fast. If you were to record the forces and speeds in an experiment, you would expect to see that the greater the force on the object, the faster it moves. If the speed of the object always increases in direct proportion to the force on it, this is known as a linear relationship.

However, as Professor Irving Epstein and his team at Brandeis University in the US have shown, not everything is that simple - particularly in chemistry. Irv heads the Nonlinear Chemical Dynamics Group which investigates systems that show much more complex, nonlinear behaviour.

So, what does it mean when a process is nonlinear? In a linear process, the outcome is linearly proportional to the input variable. Let's take the earlier example: If you pushed a box with twice as much force and the speed doubled, and then with four times as much force, and the speed quadrupled, this would be an example of a linear process. If you think of this process in terms of a graph, plotting a graph of input force against output speed would produce a straight line. But if, when you doubled the amount of force used, the speed increased by four times the amount, this would be an example of a nonlinear process. The ratio of speed to force is not constant, producing a nonlinear relationship, and plotting a graph of output speed against input force would produce a curve.

Nonlinear systems can be challenging to understand and sometimes show some unusual phenomena, including oscillatory behaviour of the observable process. Irv explains, "Common examples of nonlinearity beyond chemistry are population oscillations in a predator-prey system, like foxes and rabbits; the apparently (but not truly) random times at which a drop of water falls from a dripping faucet; the growth of the striped pattern on a tiger's coat; the fractal structure of a snowflake." While these phenomena are familiar to us, the nonlinear processes responsible for them are in fact difficult to predict and understand.

HOW DOES NONLINEARITY RELATE TO CHEMISTRY?

Oscillatory reactions are an example of nonlinear processes that occur in chemistry. These were originally discovered by accident by a Russian scientist called Boris Belousov in 


\section{ABOUT CHEMISTRY}

Chemistry is about understanding how atoms and molecules interact and react. This knowledge can be used for a wealth of applications, from designing and making new molecules to learning more about fundamental science. By studying new reactions and discovering new molecules, chemists might be able to find molecules with anti-cancer properties, for example, or for use in television displays. "These are exciting times for chemistry," says Irv. "Many of the world's most pressing issues - health, energy, climate change, water and food production require a deep understanding of chemistry."

Of course, investigations like those undertaken in Irv's Nonlinear Chemical Dynamics Group take time, and many reactions will fail, but chemistry is a varied field and the possibilities are endless! Not all chemists wear white coats and mix chemicals in flasks. A whole range of research projects are carried out by Irv's team. Of course, many of these research projects do involve conducting experiments, but some are purely theoretical and computational,

"like developing and simulating a model for the behaviour of a set of coupled chemical oscillators," explains Irv.

"Serendipity has played a significant role in this field," says Irv. "Important phenomena are often discovered while looking for something else." Belousov's discovery of oscillatory reactions is a prime example of this and highlights why keeping an open mind is so important for any scientist.

\section{CAREERS IN CHEMISTRY}

According to the US Bureau of Labor

Statistics Occupational Outlook Handbook for 2019, "Overall employment of chemists and materials scientists is projected to grow 5 per cent from 2019 to 2029, faster than the average for all occupations. Chemists and materials scientists who have an advanced degree, particularly a $\mathrm{PhD}$, are expected to have the best opportunities." So, there are many excellent career opportunities in this field.

Most chemists will work in laboratories or in research teams, where teamwork and collaboration are key skills. "A modern research group is a diverse, multigenerational community of people from all over the world," says Irv. "At any given time, our group might comprise undergraduates, graduate students, postdoctoral fellows, visiting professors, and even the occasional high school student."

"I would recommend chemistry as a career to anyone who is fascinated by trying to understand the ways in which atoms and molecules, objects far too small for us to see, interact to produce the macroscopic world in which we live," Irv continues. "If you enjoy solving these sorts of puzzles and would like to get paid to do this, you should certainly consider a career in chemistry."

\section{EXPLORE A CAREER IN CHEMISTRY}

The American Chemical Society has lots of useful information on careers in chemistry as well as educational resources:

https://www.acs.org/content/acs/en/careers. html

Similarly, the Royal Society of Chemistry has resources to help you with your studies and read about future job options for chemists:

https://edu.rsc.org/student

Irv's Nonlinear Chemical Dynamics Group welcomes graduate students and undergraduates (and an occasional high school student) to the lab. Contact research groups near you and ask them whether they will provide a tour or come into your school/college.

Search the internet for 'chemistry apprenticeships' and there could be opportunities that suit you. For example, EDF Energy (https:// careers.edfenergy.com/content/ChemistryApprenticeship/?locale=en_GB) and Nordmann (https://www.nordmann.global/en/career-withnordmann/training-programs-apprenticeshipstudies) offer chemistry apprenticeships.

According to the US Bureau of Labour Statistics, the average salary for a chemist is $\$ 77,600$.

\section{PATHWAY FROM SCHOOL TO CHEMISTRY}

Irv recommends taking classes in maths, physics and biology at school, as well as studying chemistry. Most universities will offer degrees in chemistry and, to become a research chemist, a degree will be followed by a Master's degree and/or PhD. As researchers, chemists often specialise in sub-disciplines of chemistry, such as physical, organic or inorganic chemistry, or focus on even more specific topics.

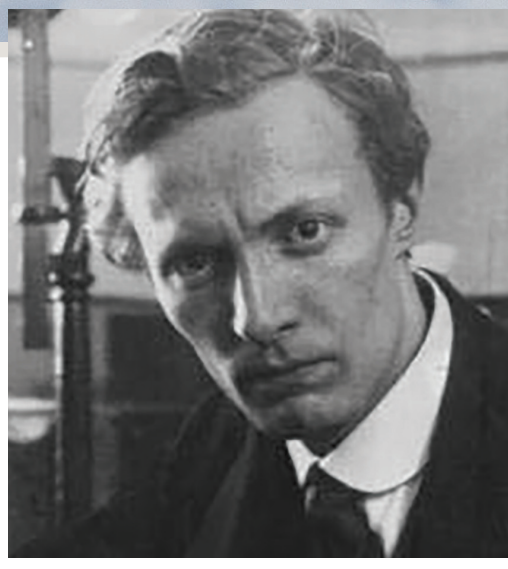

Boris Belousov, the Russian scientist who discovered an unusual oscillatory reaction in the 1950s.

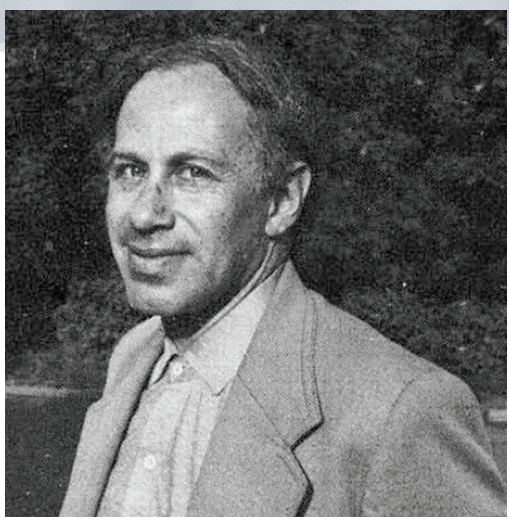

Russian chemist Anatol Zhabotinsky expanded upon Belousov's work and brought the idea of oscillatory reactions to the attention of the chemistry community. 
